Journal of Patient-Centered

Volume 4

Issue 4 -- Health Disparities and Inequities: Part

Article 27 I

$11-6-2017$

\title{
Positive Impact on Patient Satisfaction and Caregiver Identification Using Team Facecards: A Quality Improvement Study
}

\author{
Nicole M. Martin \\ Khalil Odeh \\ Lamya Boujelbane \\ Marvi V. Rijhwani \\ Susan Olet \\ Aijaz Noor \\ Colleen Nichols \\ Richard Battiola
}

Follow this and additional works at: https://aah.org/jpcrr

Part of the Health Services Administration Commons, Interprofessional Education Commons, Other Medicine and Health Sciences Commons, and the Public Health Education and Promotion Commons

\section{Recommended Citation}

Martin NM, Odeh K, Boujelbane L, Rijhwani MV, Olet S, Noor A, Nichols C, Battiola R. Positive impact on patient satisfaction and caregiver identification using team facecards: a quality improvement study. $J$ Patient Cent Res Rev. 2017;4:263.

Published quarterly by Midwest-based health system Advocate Aurora Health and indexed in PubMed Central, the Journal of Patient-Centered Research and Reviews (JPCRR) is an open access, peer-reviewed medical journal focused on disseminating scholarly works devoted to improving patient-centered care practices, health outcomes, and the patient experience. 
Background: Influenza remains a significant contributor to morbidity and mortality in the United States. Health care workers (HCW) can be both victims and vectors of influenza. Influenza vaccination of $\mathrm{HCW}$ is protective for both caregivers and patients, but voluntary programs generally fail to achieve rates recommended by the Centers for Disease Control and Prevention. Despite a complex, multifaceted influenza program initiated in 1996 that included significant education and promotion as well as free on-site vaccination, annual Aurora Health Care caregiver immunization rates remained in the mid-70s until adoption of a "condition of employment" strategy in 2011.

Purpose: Discuss the annual effectiveness of the program at achieving caregiver vaccination.

Methods: A steering committee and subgroups meet regularly to evaluate exemption requests, vaccine supply/distribution/ordering, immunization rates and general program overview. In July 2016, an online wellness survey of influenza program perceptions was offered to all Aurora caregivers.

Results: In the 2016-2017 flu season, 97.3\% of HCW were vaccinated. New medical exemption requests have varied from 72 to 127 per year, with a decreasing trend again reflecting the prevalence of permanent exemption. The number of approved annual religious exemptions grew from 39 in 2011 to 64 in 20162017. Since the initial year of implementation, when resignation of $11 \mathrm{HCW}$ was attributed to the vaccination requirement, the number of such resignations has dwindled to 2. Caregiver perceptions: 1,931 caregivers completed the online survey (approximately 6.4\% of all employees). A 5-point Likert scale was used to assess level of agreement with several statements. Caregivers expressed the highest level of agreement with the statement that "the program makes it convenient to get vaccinated" ( $89 \%$ agree or strongly agree) and the lowest level agreement with "the program keeps me healthier" (54\% agree or strongly agree).

Conclusion: An influenza program as a condition of employment leads to high levels of immunization of $\mathrm{HCW}$, with minimal impact on $\mathrm{HCW}$ retention and satisfactory satisfaction among $\mathrm{HCW}$.

\section{Positive Impact on Patient Satisfaction and Caregiver Identification Using Team Facecards: A Quality Improvement Study}

Nicole M. Martin, Khalil Odeh, Lamya Boujelbane, Marvi V. Rijhwani, Susan Olet, Aijaz Noor, Colleen Nichols, Richard Battiola

Department of Internal Medicine, Aurora Sinai Medical Center, Aurora University of Wisconsin Medical Group; Aurora Cardiovascular Services; Aurora Research Institute

Background: Patients satisfaction is an increasingly important metric in measuring the quality of care that hospitals and physicians provide. It can be difficult for patients to remember their providers and their roles, all of which may potentially impact a patient's overall satisfaction.

Purpose: To see if giving facecards with pictures and names of caregivers and description of roles improved patient satisfaction and identification of care team members.

Methods: Team facecards were designed and distributed to the patients during the interventional period of the study. Patients' identification of team members, the role of each physician and overall satisfaction was measured using a longitudinal prospective survey. Patients in the control arm of the study took the same survey but did not receive team facecards.
Results: A total of 192 patients completed the survey. They were divided into a control group $(\mathrm{n}=96,50 \%)$ and an interventional group $(\mathrm{n}=96,50 \%)$ during the period of the study (February 2016-August 2016). Patients who received the intervention were more likely to identify: their team attending (71 [74\%] in the interventional group vs $[34.4 \%]$ in the control group; $\mathrm{P}<0.001)$; team resident (40 $[40.7 \%]$ in the interventional group vs $25[26 \%]$ in the control group; $\mathrm{P}=0.0222)$; team intern (42 [43.8\%] in the interventional group vs $19[19.8 \%]$ in the control group; $\mathrm{P}=0.0004)$. Patients in the interventional group reported slightly higher level of satisfaction (72 $[75 \%]$ reported level of satisfaction $>9$ on a scale of 1 to 10 in the interventional group vs 59 [61.5\%] in the control group).

Conclusion: Use of facecards improves patient identification of primary team members and roles; however, patients still lack enough knowledge of provider roles. Use of facecards showed a slight improvement on overall patient satisfaction.

Relative Associations of Age, Height, and Weight on Sinus of Valsalva and Mid-Ascending Aorta: An Imaging and Epidemiology Study

Mirza Nubair Ahmad, Syed Haris Pir, Mirza Mujadil Ahmad, Sharmeen Hussaini, Bijoy K. Khandheria, A. Jamil Tajik, Khajawa Afzal Ammar

Department of Internal Medicine, Aurora Sinai Medical Center; Aurora Cardiovascular Services

Background: Prior studies show ascending aorta diameter varies with age, height and weight, but they did not evaluate relative influence of these variables on aortic diameter. Since height is genetically determined, and genetic disorders like Marfan syndrome are predominantly associated with sinus of Valsalva (SOV) dilation, we hypothesized height may have stronger association with SOV.

Purpose: Based on anecdotal observation, since age, weight and obesity are acquired attributes, we hypothesized age, weight and body mass index may have greater association with mid-ascending aorta (MAA) diameter, even in normal patients.

Methods: We evaluated echocardiographic studies of patients $\geq 15$ years old that were done in the last 4 years to measure SOV and MAA diameter in normal patients (defined as: medical records and echocardiograms did not reveal any of the 28 aortic dilation risk factors listed in the American Heart Association 2010 guidelines). Results: Of 65,843 patients, 3,201 were identified as normal. SOV measurements were available in 2,046, MAA in 2,334. Age had stronger correlation with MAA $(\beta=0.50 ; \mathrm{r}=0.52 ; \mathrm{P}<0.001)$ than SOV $(\beta=0.33 ; \mathrm{r}=0.35 ; \mathrm{P}<0.001)$. Weight was similarly correlated with diameters of SOV $(r=0.37 ; \mathrm{P}<0.001)$ and MAA $(r=0.37 ; \mathrm{P}<0.001)$. Height had stronger correlation with SOV diameter $(\beta=0.41 ; \mathrm{r}=0.38$; $\mathrm{P}<0.001)$ than MAA $(\beta=0.26 ; \mathrm{r}=0.25 ; \mathrm{P}<0.001)$.

Conclusion: These data suggest that in normal subjects, age, weight and body mass index have stronger associations with the midascending aorta, whereas height has a stronger association with the sinus of Valsalva. 